\title{
Peripheral Neuropathies Under New Combined Antiretroviral Therapy in HIV Infection at Fann National University Hospital: Electrophysiological Aspects and Risk Factors
} \author{
Toure $\mathbf{K}^{3}$, Seydi $\mathbf{M}^{5}$, Ndiaye $\mathbf{M}^{5}$, Diop $\mathbf{A G}^{5}$ and Ndiaye $\mathbf{M M}^{5}$ \\ ${ }^{1}$ Department of Medical Specialties, Gaston Berger University of Saint Louis, Senegal \\ ${ }^{2}$ Department Internal Medecine, Gynecological obstetrics and pediatrics hospital of Douala, Cameroun \\ ${ }^{3}$ Department Medical Specialties, Bambey University, Senegal \\ ${ }^{4}$ Department Medical Specialties, Thies University, Senegal \\ ${ }^{5}$ Department Medical Specialties, Cheikh Anta Diop University, Senegal
}

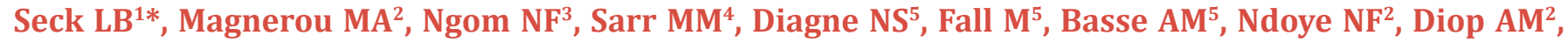

*Corresponding author: Seck Lala Bouna, Medical specialties department, Gaston Berger University of Saint Louis, Saint Louis - Senegal.

Received Date: November 11, 2019

Published Date: November 20, 2019

\section{Abstract}

Introduction: Peripheral neuropathies are frequent during HIV infection, sometimes du to antiretroviral treatment. We aimed to assess electrophysiological aspects of peripheral neuropathies occurring after initiation of new combined antiretroviral therapy, and their risk factors.

Patients and Methods: We conducted a longitudinal descriptive and analytical study in the Fann National University Hospital, recruiting patients with HIV, newly treated with new highly active antiretroviral therapy. We collected clinical, electroneuromyographical and biological data.

Results: Data of 37 patients were analyzed. Sex-ratio was of 0,68; mean age was 34,32+/- 8,03 years, and the main age group 20-40 years. The most frequent treatment combination was tenofovir + emtricitabine + efavirenz. Clinical examination found sensory neuropathy in 3 patients. Electroneuromyography confirmed these 3 cases that were sensory axonal polyneuropathy and found one case of motor axonal mononeuropathy. We did not find any correlation between neuropathy and parameters we studied.

Keywords: Neuropathies; Combined; Antiretroviral; Therapy; HIV; Fann; Electrophysiological

Abbreviations: HIV: Human Immunodeficiency Virus; ART: Antiretroviral Therapy; Cart: Combined Antriretroviral Therapy; PN: Peripheral Neuropathy; PLHIV/AIDS: People Living with HIV and/or Acquired Immunodeficiency Syndrome; CTA: Centre De Traitement Ambulatoire; HIV1: Human Immunodeficiency Virus 1; HIV2: Human Immunodeficiency Virus 2; ENMG: Electroneuromyography; BPNS: Brief Peripheral Neuropathy Screen; MRC: Medical Research Council; WHO: World Health organization; IBM SPSS: International Business Machines Corporation Statistical Package for the Social Sciences; NRTI: Nucleosidic Reverse Transcriptase Inhibitor; PWHIV: People Living with Human Immunodeficiency Virus; Nnrtis: Non Nucleosidic Reverse Transcriptase Inhibitors; FTC: Emtricitabine; TDF: Tenofovir; EFV: Efavirenz; 3TC: Lamivudine; AZT: Zidovudine; PI: Protease Inhibitor; Lpv/R: Lopinavir/Ritonavir

\section{Introduction}

The pandemic of human immunodeficiency virus (HIV) infection still remains a concern in Africa. Neurological disorders are the third complication of this infection, after digestive and dermatological ones [1]. Among these neurological complications, peripheral neuropathies are frequent [2], either due to the virus or to the neurotoxic side effects of some of the antiretroviral therapies (ART) [3]. The therapeutic management of patients infected by HIV has been greatly improved by new combined Antiretroviral Therapy (cART). However, many drugs have been recognized as responsible for the occurrence of toxic neuropathies in these patients $[3,2,4]$. 
The aim of this study was to determine the electrophysiological aspects of peripheral neuropathies (PN) and their promoting factors during initiation of cART in people living with HIV and/or acquired immunodeficiency syndrome (PLHIV/AIDS) in a hospital in Dakar.

\section{Patients and Methods}

We carried out a longitudinal analytic and prospective study between January 1st 2016 and july1st 2017, in Fan National Teaching Hospital in Dakar. It took place in two sites. On one hand, patients were recruited and benefited from clinical and biological examinations in the outpatient center for HIV/AIDS management, called «Centre de Traitement Ambulatoire = CTA), and where PLHIV/ AIDS are treated. On the other hand, the electroneuromyographic examinations were performed in the neurophysiological division of the neurological service. We included in this study, PLHIV1 or HIV2 or both, who were followed-up in the CTA, 18 years old at least, newly treated with cART and without any manifestation of PN before the intitiation of cART. We did not include those who did not consent to participate to the study, those who suffered from a disease that could provoque PN and those suffered from cognitive disorders.

We collected the following data from eligible patients: past medical history, data from physical examination, and from complementary examinations including electroneuromyography (ENMG) and biological tests. During clinical examination, we evaluated nervous system, muscle strength rating with the Brief Peripheral Neuropathy Screen (BPNS) that is used to make the clinical diagnosis of sensory PN [5]; the MRC (Medical Research Council, 1943) scale for motor deficit rating. ENMG consisted of the neurography of the following nerve trunks on both left and right sides: median, ulnar, peroneal, tibial, sural, musculocutaneous. In addition, some muscles were detected, according to the clinical context and the results of the nerves stimulations. Some biological tests were systematically realized during the follow-up, including HIV typing, viral load, CD4 rate, blood glucose, C viral hepatitis serology, kidneys and liver functions, cytomegalovirus serology. Additional second-line examinations were performed, regarding clinical context and etiological orientation.

The evolutionary status of the HIV infection was defined towards the World Health Organization (WHO) system of classification of the disease stages in adults and adolescent in 2005 [6]. Patients were seen at follow-up after 1 month, then 6 months and one year, for clinical, biological and electroneuromyographic reassessment. All data were collected on a standardized form, then entered on excel software. The statistical analysis was carried out with the software IBM SPSS Statistics 23.0. Qualitative variables were analyzed using the Fisher test, and quantitative variables using the Wilconxon test. Significance was considered for $\mathrm{p} \leq 5 \%$ for all data.

We got the agreement of the national ethical committee for research in health.

\section{Results}

Among the 71 new patients that were eligible for the cARV treatment, 47 met the inclusion criteria, 8 were lost sight and 2 were dead. So we analyzed data of 37 patients. They all benefited from a regular clinical follow-up and $25(67,57 \%)$ from regularly repeated ENMG. The sample was composed of 22 females $(59,46 \%)$ and 15 men $(40,54 \%)$ with a sex-ratio of 0,68 . The mean age was de $34,32+/-8,03$ years, with age varying from 22 to 65 years. The mainly represented age group was $20-40$ years (78\%).

Thirty-two patients $(86,48 \%)$ were infected with HIV1, 4 $(10,81 \%)$ with HIV2 and $1(2,70 \%)$ with both viruses. Twentysix $(70,27 \%)$ patients belonged to stage 2 of WHO system of classification of HIV infection and AIDS in adults and adolescents, $6(16,22 \%)$ belonged to stage 3 and $5(13,51 \%)$ to stage 1 . CD 4 rate was inferior to 500 cells $/ \mathrm{mm} 3$ in $92 \%$ of patients.

The most frequent therapeutic combination was tenofovir + emtricitabine + efavirenz, that was administered to 31 patients $(83.78 \%)$ all infected with HIV1. The second one was lamivudine + tenofovir + (lopinavir + ritonavir) administered to 5 patients (13.51\%), among which 3 were infected with HIV2, one with HIV1 and one with both viruses, the one with HIV1 having hepatic deficiency. The third protocol, lamivudine + zidovudine + tenofovir, was administered to 1 patient $(2.70 \%)$ infected with HIV2. None of the protocols was modified over the course of the study. Throughout the follow-up, the mean rate of CD4 increased from 360 to 590 cells $/ \mathrm{mm}^{3}$, the same for the mean viral load that went from 145986 copies/ml at the beginning of the treatment to less than 50 copies/ $\mathrm{ml}$ (undetectable).

On the clinical side, no patient had complained of neuropathic pain or other sensory trouble during the whole follow-up. Physical examination showed epicritic hypoesthesia, and hypopallesthesia in lower limbs in 3 patients, associated with a score of 3/10 on the BPNS, reflecting a slight sensitive neuropathy. We did not find any clinical disorder suggestive of motor neuropathy.

In 4 cases $(10,8 \%)$ (Table 1), ENMG made possible the diagnosis of PN at 1 month of follow-up in 4 patients, by confirming sensitive axonal polyneuropathy in the 3 patients that were clinically affected and revealing an axonal motor mononeuropathy not clinically detected. They were 2 males and 2 females. All had neuropathy of the lower limbs. Neurography revealed an important decrease in amplitude of sensitive potential of the 2 musculocutaneous nerves in 1 patient ( $\mathrm{N}^{\circ} 2$ of Table 1 ), with amplitudes values of $2,8 \mu \mathrm{V}$ on right side and $3,2 \mu \mathrm{V}$ on left side, the conduction velocities being maintained on both. Two others had decrease in amplitude of sensitive potential of the 2 sural nerves, respectively $3,4 \mu \mathrm{V}$ on right side and $4 \mu \mathrm{V}$ on left side for one (patient $\mathrm{N}^{\circ} 1$ of Table 1) and $2,5 \mu \mathrm{V}$ on rignt side and $2,9 \mu \mathrm{V}$ on left side for the other (patient $\mathrm{N}^{\circ} 3$ of Table 1). Conduction velocities of sensitive nerves were normal. We put the diagnosis of sensory axonal polyneuropathy of lower limb for these 3 patients. The fourth patient ( $\mathrm{N}^{\circ} 4$ of Table 1 ) had low 
amplitude of the motor potential on left peroneal nerve $(0,8 \mathrm{mV})$, with other conduction parameters that were normal (motor distal latency, conduction velocity, F wave latency). We put the diagnosis of motor axonal mononeuropathy of left peroneal nerve (Table 1). We did not find any new case of PN neither at 6 month of follow-up, nor at one year (Table 1).

Table 1: Electroneuromyographic abnormalities found in the series.

\begin{tabular}{|c|c|c|c|c|c|c|}
\hline \multirow[b]{2}{*}{ Patients } & \multirow[b]{2}{*}{$\begin{array}{l}\text { Gender/ Age } \\
\text { (years) }\end{array}$} & \multirow[b]{2}{*}{$\begin{array}{l}\text { Clinical Mani- } \\
\text { festations }\end{array}$} & \multicolumn{3}{|c|}{ Electroneuromyography } & \multirow[b]{2}{*}{ Diagnosis } \\
\hline & & & Affected Nerves & $\begin{array}{c}\text { Potential Amplitude } \\
\text { of Nerves of } \\
\text { Affected } \\
\text { Patients }\end{array}$ & $\begin{array}{l}\text { Potential } \\
\text { Amplitude of } \\
\text { Nerves in } \\
\text { the Series }\end{array}$ & \\
\hline $\mathrm{N}^{\circ} 1$ & $\mathrm{~F} / 47$ & $\begin{array}{c}\text { Proprioceptive } \\
\text { disorders of } \\
\text { lower limb }\end{array}$ & $\begin{array}{l}\text { Sensitive nerves } \\
\text { - Right sural } \\
\text { - Left sural }\end{array}$ & $\begin{array}{c}3,4 \mu \mathrm{V} \\
4 \mu \mathrm{V}\end{array}$ & $7-32 \mu \mathrm{V}$ & $\begin{array}{l}\text { Axonal sensitive } \\
\text { polyneuropathy }\end{array}$ \\
\hline $\mathrm{N}^{\circ} 2$ & $\mathrm{~F} / 24$ & $\begin{array}{l}\text { Proprioceptive } \\
\text { disorders of } \\
\text { lower limb }\end{array}$ & $\begin{array}{l}\text { Sensitive nerves } \\
\text { - Right } \\
\text { musculocutaneous } \\
\text {-Left } \\
\text { musculocutaneous }\end{array}$ & $\begin{array}{l}2,8 \mu \mathrm{V} \\
3,2 \mu \mathrm{V}\end{array}$ & $10-47 \mu \mathrm{V}$ & $\begin{array}{l}\text { Axonal sensitive } \\
\text { polyneuropathy }\end{array}$ \\
\hline $\mathrm{N}^{\circ} 3$ & $\mathrm{M} / 40$ & $\begin{array}{c}\text { Proprioceptive } \\
\text { disorders of } \\
\text { lower limb }\end{array}$ & $\begin{array}{l}\text { Sensitive nerves } \\
\text { - Right sural } \\
\text { - Left sural }\end{array}$ & $\begin{array}{l}2,5 \mu \mathrm{V} \\
2,9 \mu \mathrm{V}\end{array}$ & $7-32 \mu \mathrm{V}$ & $\begin{array}{l}\text { Axonal sensitive } \\
\text { polyneuropathy }\end{array}$ \\
\hline $\mathrm{N}^{\circ} 4$ & $\mathrm{M} / 26$ & Subclinical & $\begin{array}{l}\text { Motor nerves } \\
\text { - Left peroneal }\end{array}$ & $0,8 \mathrm{mV}$ & $3-12 \mathrm{mV}$ & $\begin{array}{c}\text { Axonal motor } \\
\text { mononeuropathy }\end{array}$ \\
\hline
\end{tabular}

F: female - M: male

Table 2: Patients and virological characteristics and correlations with the neuropathy.

\begin{tabular}{|c|c|c|c|c|}
\hline & & \multicolumn{3}{|c|}{ Patients } \\
\hline \multirow{2}{*}{\multicolumn{2}{|c|}{ Variables on Study }} & Patients PN- & Patients PN+ & $P$ value \\
\hline & & $\mathbf{N}=\mathbf{3 3}$ & $N=4$ & \\
\hline \multirow{2}{*}{$\begin{array}{l}\text { Socio-demographic } \\
\text { characteristics }\end{array}$} & Mean age + range (years) & $\begin{array}{c}34,3 \\
(22-65)\end{array}$ & $\begin{array}{c}34,2 \\
(24-47)\end{array}$ & 0,08 \\
\hline & Gender (M/F) & $13 / 20$ & $2-\mathrm{Feb}$ & 0.37 \\
\hline \multirow{4}{*}{$\begin{array}{c}\text { Immuno-Virological } \\
\text { Status }\end{array}$} & $\begin{array}{l}\text { CD4 mean rate + range } \\
\left(\text { cells } / \mathrm{mm}^{3}\right)\end{array}$ & $\begin{array}{c}\text { M0: } 360(40-798) \\
\text { M1: } 466(109-868) \\
\text { M6: } 532(152-1013) \\
\text { M12: } 590(251-859)\end{array}$ & $\begin{array}{c}\text { M0: } 311(54-521) \\
\text { M1: } 409(164-617) \\
\text { M6: } 352(150-553) \\
\text { M12: } 630(450-800)\end{array}$ & 0,08 \\
\hline & $\begin{array}{l}\text { Mean viral load + range } \\
\quad(\text { copies } / \mathrm{ml})\end{array}$ & $\begin{array}{c}\text { M0: } 145986 \\
(1070-834088) \\
\text { M1: } 424(0-1789) \\
\text { M6: } 67(0-528) \\
\text { M12: } 26(0-289)\end{array}$ & $\begin{array}{c}\text { M0: } 300606 \\
(4973-705817) \\
\text { M1: } 414(56-939) \\
\text { M6: } 17(0-71) \\
\text { M12: } 72(0-280)\end{array}$ & 0,8 \\
\hline & $\begin{array}{c}\text { HIV } 1 \\
\text { HIV } 2 \\
\text { HIV1+ HIV2 }\end{array}$ & $\begin{array}{c}28 \\
4 \\
1\end{array}$ & $\begin{array}{l}4 \\
0 \\
0\end{array}$ & $\begin{array}{l}0,65 \\
0,7 \\
0,9\end{array}$ \\
\hline & $\begin{array}{l}\text { WHO stage } \\
\qquad \begin{array}{c}1 \\
2 \\
3 \\
4\end{array}\end{array}$ & $\begin{array}{c}5 \\
22 \\
6 \\
0\end{array}$ & $\begin{array}{l}0 \\
4 \\
0 \\
0\end{array}$ & $\begin{array}{l}0,5 \\
0,9 \\
0,9 \\
-\end{array}$ \\
\hline cART protocol & $\begin{array}{c}\text { NRTI+NNRTIs } \\
\text { FTC+TDF+EFV } \\
\text { 3TC+AZT+TDF } \\
\text { NRTI+PI } \\
\text { 3TC+TDF+Lpv/r }\end{array}$ & $\begin{array}{c}28 \\
1 \\
4\end{array}$ & $\begin{array}{l}4 \\
0 \\
0\end{array}$ & $\begin{array}{l}0,7 \\
0,9 \\
0,8\end{array}$ \\
\hline
\end{tabular}

Patients PN-: patients without peripheral neuropathy - Patients PN+: patients with peripheral neuropathy - M: male - F: female - HIV1: human immunodeficiency virus 1 - HIV2: human immunodeficiency virus 2 - M0, M1, .. MX: month zero, month one, .... month X of follow-up - WHO: World Health Organization - cART: combined antiretroviral therapy - NRTI: nucleosidic reverse

transcriptase inhibitor - NNRTIs: non nucleosidic reverse transcriptase inhibitors - FTC: emtricitabine

TDF: tenofovir - EFV: efavirenz - 3TC: lamivudine - AZT: zidovudine - PI: protease inhibitor - Lpv/r: lopinavir/ ritonavir. 
We did not notice a statistically significant correlation between the occurrence of the PN on one hand and on the other hand: age, gender, the type of virus, the WHO stage of HIV infection and AIDS, the rate of CD4 and the viral load (Table 2).

\section{Discussion}

$>$ Age is similar to what is reported in the different works in literature, like Zanetti et al. [7] and Sapna et al. [8]. According to many studies, both genders are vulnerable to PN related to HIV and ART toxic side effects, some of these studies having been conducted in sub-Saharan Africa $[9,10,8,11]$. We did not find any gender predominance, unlike what is reported by Sapna et al. [8] who showed a slight female predominance $(65,3 \%)$.

$>$ The mean viral load at the beginning of our study was higher among those who have developed a PN later, but at one month of follow-up, the mean values of the loads were comparable: 424 copies/ml in individuals without PN and 414 copies/ml in the group with PN. Current data do not correlate PN occurrence with viral load [12].

> All the patients who have developped PN were under the first protocol (tenofovir + emtricitabine + efavirenz). This support the conclusions of studies that report cases of PN with new cART in the absence of exposure to stavudine [12-15], this latter being particularly known to be one of the most toxic on the peripheral nerves [16]. In Kenya, Ndakala FN et al. [13] found, while studying risk factors for occurrence of PN in some patients under cART, a significant difference $(\chi=6.68 \mathrm{p}=0.017)$ in the occurrence of PN with tenofovir compared to the other cART, among which stavudine. They concluded that in patients under cART, other factors are probably also at play, like metabolic or genetic, to lead to $\mathrm{PN}$.

Furthermore, nucleoside reverse transcriptase inhibitors (NRTI) like zidovudine, lamivudine and emtricitabine, are not deemed as toxic for peripheral nerves [17]. However, our first protocol, from which the 4 patients who developed PN had benefited, included a NRTI. There occur no PN under the second and the third protocols, that contained each some NRTI. Since ART were combined in our series, it is difficult to identify the intrinsic responsibility of each single one in the occurrence of the PN. We cannot consider emtricitabine (NRTI), as responsible for the PN. Nevertheless, Evans et al. also support the idea that other mecanisms are involved in addition to the toxicity of the ART, such as metabolic, pharmacokinetic and genetic or a transient systemic inflammatory response syndrom at the early stage of the initiation of cART [17].

The 3 patients under protease inhibitor (lopinavir + ritonavir), did not develop PN. This has been reported in some hospital-based studies [18], even if other studies suggest the involvement of some of them as PN risk factors [19].

$>$ After one month of follow-up, there was no clinical complaint, while physical examination of 3 patients showed abnormalities consistent with proprioceptive disorders of lower limbs. ENMG confirmed these 3 cases as sensitive axonal polyneuropathy and found 1 case of axonal motor mononeuropathy that was not clinically overt. It is said that sensitive neuropathy remains prevalent during HIV infection/AIDS despite the new cART [12]. The sensory polyneuropathies we found in 3 cases are the most frequently described $[20,14]$. They occur most of the time at an advanced stage of immunodepression but can be due to neurotoxicity of some ART. Zaneti et al. [7] made the diagnosis of essentially chronic polyneuropathies and mononeuropathies, based on ENMG.

Proprioceptive manifestations seem to be prevailing among sensitive neuropathies, according to Amruth G et al. [21]. But, if we consider that a disorder of small fibers of superficial sensitivity not clinically overt can be misdiagnosed by standard ENMG, the prevalence of proprioceptive manifestations among sensitive disorders could be challenged. The predominance of sural nerve damage ( 2 cases among 3 sensitive PN in our study) is also noticed by Amruth et al. [21], whose study revealed an exclusive damage of sural nerves in 22 PWHIV, of whom 18 were treated with ART.

Many cases of subclinical PN have been reported towards studies, the diagnosis being done by ENMG with significant frequency rate round 20-33\%: Geremia et al. [22], Banerjee et al. [23], Amruth et al. [21], Zaneti et al. [7]. Thus, physicians have to take into account that they should systematically perform clinical examination of nervous system, in any PLHIV/AIDS, even in the absence of complaint, and then complete it with ENMG.

PN du to HIV are usually demyelinating neuropathies and those du to cARV axonal ones $[21,24,25,26]$. In our series, all the cases have appeared after the initiation of cART and were axonal. They were confined to lower limb like in the study conducted by Armuth et al. [21], in which neurography found abnormalities only in lower limbs, the same for Kakkad et al. [24] who reported a neuropathy of musculocutaneous and sural nerves on neurography.

\section{Conclusion}

Neuropathies occurring during HIV infection are topical. The development of less toxic ART, particularly on peripheral nerves, is a great preoccupation, especially since their toxicity is in addition to the vulnerability of the nerves to the virus pathogenicity. However, toxicity of new cART is more and more emphasized by authors, and all ART classes seem to be involved. In our study, as in the main literature data, PN seem to be prevalent on sensitive nerves, mainly of lower limbs, leading to a proprioceptive syndrome with axonal mecanism. But given that treatment is combined, it is difficult to determine with certainty the real responsibility of each drug, even if we know the toxicity of each.

\section{Acknowledgements}

Thanks to the World Federation of Neurology, for its financial support, including the clinical examination tools and the costs of biological and electroneuromyography examinations, that has enabled this study to be carried out. 


\section{Conflict of Interest}

No financial interest or conflict of interest.

\section{References}

1. Stover J, Walker N, Grassly NC, Marston M (2006) Projecting the demographic impact of AIDS and the number of people in need of treatment: updates to the Spectrum projection package. Sex Transm Infect 82(Suppl 3): 45-50.

2. Williams D, Geraci A, Simpson DM, Williams D, Geraci A et al. (2001) AIDS and AIDS-treatment neuropathies. Curr Neurol Neurosci Rep 1(6): 533-538.

3. Moulignier A (2006) Atteintes du système nerveux central et infection par le VIH-1. Rev Neurol 162(1): 22-42.

4. Wulff EA, Wang AK, Simpson DM (2000) HIV-associated peripheral neuropathy: epidemiology, pathophysiology and treatment. Drugs 59(6): 1251-1260.

5. Cherry CL, Wesselingh SL, Lal L, Mcarthur JC (2005) Evaluation of a clinical screening tool for HIV-associated sensory neuropathies. Neurology 65(11): 1778-1781.

6. WHO (2005) Interim WHO clinical staging of HIV/AIDS and HIV/AIDS case definitions for surveillance. African region. WHO /HIV/2005.02. http://www.who.int/hiv/en.

7. Zanetti C, Manzano GM, Gabbai AA (2004) The frequency of peripheral neuropathy in a group of HIV positive patients in Brazil. Arq Neuropsiquiatr 62(2A): 253-256.

8. Mehta SA, Ahmed A, Laverty M, Holzman RS, Valentine F, et al. (2011) Sex differences in the incidence of peripheral neuropathy among Kenyans initiating antiretroviral therapy. Clin Infect Dis 53(5): 490-496.

9. Cherry CL, Affandi JS, Imran D, Yunihastuti E, Smyth K et al. (2009) Age and height predict neuropathy risk in patients with HIV prescribed stavudine. Neurology 73(4): 315-320.

10. Millogo A, Sawadogo AB, Sawadogo AP, Lankoandé D (2002) Neuropathies périphériques révélatrices de l'infection par le VIH au Centre hospitalier de Bobo-Dioulasso (Burkina Faso). Bull Soc Pathol Exot 95(1): 27-30.

11. Van Griensven J, Zachariah R, Rasschaert F, Mugabo J, Atté EF, et al. (2010) Stavudine- and nevirapine-related drug toxicity while on generic fixed-dose antiretroviral treatment: incidence, timing and risk factors in a three-year cohort in Kigali, Rwanda. Trans R Soc Trop Med Hyg 104(2): 148-153.

12. Ellis RJ, Rosario D, Clifford DB, McArthur JC, Simpson D, et al. (2010) Grant I; CHARTER Study Group. Continued high prevalence and adverse clinical impact of human immunodeficiency virus-associated sensory neuropathy in the era of combination antiretroviral therapy: the CHARTER Study. Arch Neurol 67(5): 552-558.

13. Ndakala FN, Oyugi JO, Oluka MN, Kimani J, Jablonka A, et al. (2016) Prevalent neuropathy in a cohort of HIV-infected Kenyan sex workers using antiretroviral drugs. Pan Afr Med J 25: 14.
14. Verma S, Micsa E, Estanislao L, Simpson D (2004) Neuromuscular complications in HIV. Curr Neurol Neurosci Rep 4(1): 62-67.

15. Van Oosterhout JJ, Bodasing N, Kumwenda JJ, Nyirenda C, Mallewa J, et al. (2005) Evaluation of antiretroviral therapy results in a resource-poor setting in Blantyre, Malawi. Trop Med Int Health 10(5): 464-470.

16. Njoroge J, Reidy W, John-Stewart G, et al. (2009) Incidence of Peripheral Neuropathy Among Patients Receiving Stavudine vs. Zidovudine. Abstract of the IAS Conference on HIV Pathogenesis, Treatment and Prevention. Cape Town, South Africa: IAS.

17. Evans SR, Lee AJ, Ellis RJ, Chen H, Wu K, et al. (2012) HIV peripheral neuropathy progression: protection with glucose-lowering drugs? J Neurovirol 18(5): 428-433.

18. Haute autorité de santé (2007) Prise en charge diagnostique des neuropathies périphériques (polyneuropathies et mononeuropathies multiples). Service des recommandations professionnelles 2007.

https://www.has-sante.fr/portail/upload/docs/application/pdf/ diagnostic_neuropathies_peripheriques_recommandations.pdf. $\quad$ (10 juillet 2017)

19. Barohn RJ, Gronseth GS, LeForce BR, McVey AL, McGuire SA, et al. (1993) Peripheral nervous system involvement in a large cohort of human immunodeficiency virus-infected individuals. Arch Neurol 50(2): 167171.

20. Moulonguet A (2003) Neuropathies périphériques au cours de l'infection par le VIH. Rev Neurol 159(12): 1223-1226.

21. Amruth G, Praveen-kumar S, Nataraju B, Nagaraja BS (2014) HIV associated sensory neuropathy. J Clin Diagn Res 8(7): MC04-MC07.

22. L Geremia, G Pastorino, P Sergi, R Doronzo, G Sacilotto, et al. (1995) Subclinical peripheral neuropathy in HIV infection: an electrophysiological study. Electroencephalogr Clin Neurophysiol 95(3): 66.

23. Banerjee S, McCutchan JA, Ances BM, Deutsch R, Riggs PK, et al. (2011) Hypertriglyceridemia in combination antiretroviral-treated HIVpositive individuals: potential impact on HIV sensory polyneuropathy. AIDS 25(2): F1-F6.

24. Kakkad A (2012) Effect of Human Immunodeficiency Virus Infection on Nerve Conduction Velocity Study in Neurologically Asymptomatic Patients. Indian J Physiother Occup Ther 6(1): 44-47.

25. Kanabar G, Nagendran K (2006) P09.4 Demyelinating peripheral neuropathy in HIV infection. Clinical Neurophysiology 117 (Suppl 1): 176

26. Lefaucheur JP, Creange A (2004) Neurophysiological testing correlates with clinical examination according to fibre type involvement and severity in sensory neuropathy. J Neurol Neurosurg Psychiatry 75(3): 417-422. 